\title{
Japón: su economía al día de hoy
}

\author{
Enrique Subercaseaux
}

El autor señala que si bien las economías difieren entre sí, es esencial analizarlas enfatizando las diversidades y captando las semejanzas. Comúnmente a Japón se le considera una economía diferente al resto, sin embargo, como aquí se explica, sus problemas estructurales y su actual recesión económica pueden compararse con lo que ocurre en otros lugares. En el corto plazo, hay una analogía con Estados Unidos (1984-92), Inglaterra (1985-93) y otros países angloamericanos; en el largo plazo, tiene similitudes con Francia. Simultáneamente, es fundamental reconocer los rasgos propios de este país que podrian transformar la situación presente. Entonces, se concluye que en Japón la reforma estructural debe pasar por un proceso de desregulación burocrática que, si bien concita consenso, es difícil implementarlo, para lo cual lo deteminante sería el cambio político, es decir la constitución de un gobiemo estable con una sólida mayoria parlamentaria.

Muchos analistas occidentales, tanto del ámbito económico como politico, presentan a Japón como una economía (o un país) que es totalmente diversa al resto. Incluso algunos escritores japoneses caen en la misma táctica, con el consiguiente regocijo de aquellos analistas occidentales que pertenecen a la escuela "Japón-es-totalmente-distinto".

Esta aproximación nos parece tanto liviana como estéril.

Cada economía es distinta, en alguna medida, de la siguiente. Cada cultura posee elementos que le son específicos. La labor del analista, y de quien diseña políticas, es enfatizar las diferencias y captar las similitudes. 
Si se ignoran las similitudes se corre el riesgo de aprender la experiencia de las otras naciones. La economía no posee una equivalencia con los experimentos de un científico bajo condiciones de laboratorio. Todo con lo que se cuenta son datos de eventos en otras latitudes y en el pasado, que buscan ser aprehendidos haciendo uso de modelos experimentales algo artificiosos y el desarrollo de la teoría intelectual. El economista debiera reconocer las limitantes de tal aproximación, absteniéndose de emitir juicios y/o predicciones excesivamente optimistas. Pero, al mismo tiempo, debe reconocerse que las alternativas son las de operar en la oscuridad.

Es, al mismo tiempo, peligroso ignorar las diferencias entre las naciones y entre los diversos períodos históricos. Los marcos institucionales varían enormemente de un país a otro, así como las respuestas de los individuos o las empresas a estímulos económicos específicos. Las economías no son máquinas capaces de entregar (o producir), en forma constante, una cantidad predeterminada de productos al recibir una cantidad predeterminada de insumos. Son demasiado complicadas, muy variables y excesivamente humanas para que logren-un patrón productivo constante. Ello es lo que las hace interesantes, así como fuentes de frustraciones, para cualquiera que desee llegar invariablemente al fondo de los problemas.

En el caso de Japón, encontramos dos tipos de "similitudes" internacionales que son útiles para explicar las perspectivas económicas del país, al mismo tiempo que proveer algunos indicadores de lo que podría deparar el futuro. La primera es, esencialmente, de corto plazo: la actual recesión económica en Japón es, principalmente, de carácter angloamericano. La segunda es de largo plazo: los temas estructurales de la economía japonesa son, en muchos aspectos, similares a los de Francia. En el análisis de ambas analogias nos parece importante reconocer, al mismo tiempo, aquellas características peculiares a Japón que pueden potencialmente transformar la situación en algo distinto.

Comencemos con ei corto plazo. Son pocos los analistas del tema Japón, en los Estados Unidos, que concordarian con el aserto que el reciente ciclo económico de ese país puede ser descrito como angloamericano. Sin embargo, puede muy bien serlo. ¿Por qué? Porque el ciclo de crecimiento y contracción que vivió ese país entre 1986-1996 fue similar, en cuestiones esericiales, al que experimentó Estados Unidos en 19841992, Inglaterra en 1985-1993 e incluso otros países como Suecia, Australia y Canadá. 
Estos períodos de crecimiento fueron impulsados por el sector financiero. Todos pasaron por un período de liberalización parcial del sector financiero, el cual permitió a sus instituciones efectuar préstamos, invertir y expandirse a nuevas áreas de negocios con mucha mayor libertad. Los clientes corporativos variaron sus métodos para obtener financiamiento, como una reacción a estos acontecimientos. Los precios de los bienes raíces aumentaron vertiginosamente, transformando este sector de la economía en una actividad especulativa. Los bancos aumentaron la colocación de préstamos y los índices bursátiles subieron. Los consumidores comenzaron a endeudarse a tasas nunca antes vistas (en relación a sus ingresos).

Al poco tiempo explotó la burbuja. El término del ciclo de crecimiento varió de país a país. El de Estados Unidos comenzó én 1987, aunque el sector inmobiliario mostró una mayor rigidez, sucumbiendo sólo dos años después. El de Inglaterra sucedió en 1989-1991. La Bolsa de Tokyo comenzó a bajar durante enero de 1990, aunque el impacto en la economía y el sector inmobiliario se hizo obvio sólo dos años después.

Las características básicas de estas economías, al momento de su contracción, han sido muy similares. La palabra clave en todos estos casos ha sido una: deuda. Las compañías acumularon una deuda excesiva. Los especuladores en el área inmobiliaria fueron a la quiebra. Los consumidores se encontraron en una situación de alta deuda y bajos ingresos, reaccionando con una brusca contracción en sus patrones de consumo. Todos estos agentes dejaron a los bancos con un problema de deudas impagas.

Como consecuencia, Inglaterra, Estados Unidos y los demás países sufrieron una larga y lenta recesión. La confianza del consumidor bajó a causa de un shock por sobreendeudamiento y, en particular, por la baja en los precios de los bienes raíces. Las empresas buscaron sanear sus deudas. Los bancos iniciaron un complicado proceso de limpieza de sus libros contables y de renegociación paulatina de su cartera vencida. Con el fin de rehacer su capital, los bancos buscaron aumentar sus ganancias operativas, bajando las tasas de interés ofrecidas por captaciones à un ritmo más rápido que el decrecimiento de las tasas de interés por colocaciones, procesos que de por sí entrampó la recuperación de la economía.

Esta situación se replicó en Japón de manera casi exacta.

La recesión 1992-1996 estuvo dominada por los problemas en el sector financiero y por los esfuerzos de los bancos en pro de la reconstrucción de su capital y tasas de ganancias. La tasa de ahorro interno 
comenzó a aumentar debido a que la confianza del consumidor estaba en un nivel muy bajo.

Dos hechos a comínzos del año 1995 afectaron el proceso de recuperación en el patrón de gastos del consumidor: el terremoto del mes de enero y la ola de atentados terroristas de la secta Aum.

La fortaleza del presupuesto fiscal en el período 90-92 fue un factor que atenuó la ola recesiva, ya que le permitió una expansión en el gasto público durante el período 92-96; el cual tuvo como consecuencia un aumento en la demanda y la creación de nuevas fuentes laborales en el sector construcción.

El sector financiero continúa su dominio en la economía durante 1996, como un factor coadyuvante a la recuperación economica. Así como en el caso de Inglaterra (1993) y Estados Unidos (1992), Japón está entrando en un lento proceso de recuperación económica. El consumo privado va en aumento. Los bancos empiezan a atisbar la luz al final del túnel, especialmente a raiz del paquete de ayuda financiera que el gobiemo diseñó para resolver el problema de las instituciones financieras para la vivienda, denominadas jusen. La estabilidad del yen a un nivel de 104-107 por dólar norteamericano (un 20\% de depreciación con respecto de mediados de 1995) ha brindado un respiro al sector exportador.

Tanto en Inglaterra como en los Estados Unidos la recuperación se notó casi apenas al principio: tomó entre uno y dos años para marcar un patrón de recuperación inequivoco.

En Inglaterra el proceso fue algo más lento debido a que el gobiemo se vio forzado a aumentar los impuestos con el objeto de disminuir el déficit fiscal. Esta situación podría replicarse fácilmente en Japón, donde el Ministerio de Finanzas sostiene que los paquetes de reactivación financiera han sido demasiado generosos y que durante 1997 debenia tenderse a una disminución del gasto vía aumento de los impuestos. De ser asi, constituiria un freno al proceso de reactivación económica.

Una economía con todas las tortalezas de Japón no puede permanecer por mucho tiempo en un ciclo recesivo. Su tecnología de avanzada se aplica ampliamente en los procesos productivos, el nivel de educación es muy alto y parejo, y las tasas de ahorro son altas. Con estos factores, la economía debería experimentar un nuevo periodo de crecimiento, replicando aquellos ciclos de las décadas de los 70 y 80 . La interrogante es cuándo y cuánto. 
Es en este punto donde una segunda comparaciǒn parece pertinènte. En el corto plazo Japón encuentra similitudes con los ciclos económicos de Estados Unidos e Inglaterra. Pero, en el largo plazo, Francia ofrece uná analogía más completa. Esa nación comparte ciertas importantes características con Japón: su sistema educacional provee un producto de alto nivel y calidad para el estudiante medio; sus trabajadores gozan de un alto nivel de protección social; el Estado cumple con un rol orientador importante en el ámbito de las grandes empresas privadas; $y$, por último, la burocracia tiene una larga tradición de intervención en el ámbito económico y social, como un cuerpo de élite.

Así como Japón, Francia ha sido un país exitoso. Muchos olvidan que sus tasas de crecimiento durante las décadas de 10560 y 70 fueron aún más altas que Alemania. Sin embargo, al igual que Japón, Francia hä encontrado crecientes próblemas para continuar con su proceso de crecimiento y aumento en el nivel de vida durante los últimos 15 años.

El Estado sigue siendo intervencionista y la protección (o red) social es aún extensa, al mismo tiempo que el nivel educacional se mantiene alto. Empero, la fórmula ya no es capaz de dar los positivos resultados del pasado. Parece existir una pérdida en el vigor social y económico, el cual permitía un alto ritmo de actividad. Francia acarrea lastres pesados. Su sistema de seguridad social es muy costoso, tanto para el contribuyente como para el empleador. Su Estado intervencionista ha caído en onerosos errores como, por ejemplo, el haber impulsado a uno de los bancos estatales, Credit Lyonnais; a un proceso de fuerte inversión en la industria y en el exterior, estrategia que acarreó grandes pérdidas. Grupos de presión, tales como los sindicatos del sector público y los agricultores, resisten el proceso de cambios y ajuste. El nivel de desempleo es de un $11,7 \%$ aun más alto que Alemania (10\%) e Inglaterra (8\%).

La analogía con Japón tiene dos vertientes: primero, una fórmula que fue exitosa al aplicarse en el pasado ya no funciona tan bien en el día de hoy. Es posible que la intervención estatal no fuese la causa directa del crecimiento económico de Francia, pudiendo haber sido sólo una de las causales del crecimiento. Esta es sólo una conjetura, pero el hecho es que, tal como en el caso de Japón, la intervención estatal no ha sido la panacea de prosperidad, como alguna vez lo fue en el pasado.

Segundo, el hecho que un país que presenta ciertas fortalezas básicas puede continuar en una senda de crecimiento por un largo tiempo, a pesar de cargar con un fuerte lastre, los cuales, eventualmente y de manera puntual, causan trastomos dentro de la economía. 
En síntesis, esta es nuestra visión de la economía de Japón hoy en día. $\mathrm{Su}$ economía sufre de algunos problemas estructurales. El sistema de seguridad social, a través de un sistema de empleo de por vida, es extenso y costoso. Grupos de presión, ya sea de ciertos sectores industriales (tales como la construcción y telecomunicaciones), o bien grupos tales como los agricultores o empleados del sector postal, han erigido fuertes barreras para defenderse y resistir un proceso de cambios, ya que ellos se han beneficiado enormemente bajo el actual sistema económico. La burocracia estatal, en particular el Ministerio de Firianzas, está convencida que es su derecho intervenir en cualquier sector de la economía, pero es, al mismo tiempo, inmune a las críticas.

A pesar de estas cargas, la estructura económica japonesa es de tal fortaleza que no debería tener mayores problemas para lograr tasas de crecimiento aceptables durante el resto de esta década. Sus empresas son financieramente sólidas, innovadoras y bien administradas y, en ocasiones, en la punta del proceso de innovación tecnológica. La fuerza laboral está bien entrenada y educada. Las tasas de ahorro continúan altas. La deuda gubernamental es moderada.

La subsistencia de desequilibrios e ineficiencias en la economía indican problemas en aumento hacia el futuro. A pesar de no tener inmigración y una población estable, las tasas de desempleo van en una lenta tendencia alcista. Con el cambio de milenio, la pirámide poblacional sufrirá un proceso de envejecimiento pronunciado. Como consecuencia directa, aumentarán los costos de la seguridad social y la salud, y las tasas de ahorro tenderán a la baja. El crecimiento de la economía se tornará más dificil y los impuestos tenderian a subir. Al mismo tiempo, el país no se encontraría en un buen pie para hacer frente a algún shock, de características internas o externas, que afectaría directamente al proceso de crecimiento.

La altemativa lógica es hacer frente a los problemas existentes durante los próximos años. Si se toma tal curso de acción, un periodo de crecimiento moderado podría transformarse en algo más excitante, posibilitando al país construir una base más sólida desde la cual atacar el problema del envejecimiento poblacional en el mediano plazo. Pero tomar estas decisiones será algo muy dificil. Es aqui donde las diferencias y peculiaridades de cada economía y sociedad entran a jugar un rol determinante, y es labor complicada establecer paralelos con otros países. Las líneas gruesas de la necesaria reforma estructural pueden ser dibujadas de una manera muy simple: liberar las energías y recursos que se encuentran actualmente entrampados en una madeja de reglamenta- 
ción restrictiva, lo que distorsiona las decisiones económicas y las estructuras de precios.

Liberar energías y recursos es una medida que fácilmente concita al consenso, lo cual explica que todos en Japón sean partidarios de un proceso de desregulación. Empero, lograrlo no es tan simple. Un real proceso de desregulación ayudará a la economía, pero afectando a ciertas áreas específicas de ella. Habrán ganadores y perdedores. Entre estos últimos se encontrará la burocracia, ya que el punto central del proceso de desregulación será reducir el poder discrecional e intervencionista de los grandes ministerios del área económica.

Sólo la política, y los políticos, pueden en el último término crear los espacios para tomar estas decisiones dificiles; las cuales causarán pérdidas económicas tanto a los agricultores como a los pequeños comerciantes, pero que irían en beneficio directo de la mayoría. A la postre, el factor crucial para el cambio económico en Japón será el cambio (o bien evolución) político. Será necesario un reajuste en las fuerzas políticas, produciendo un gobierno estable con una sólida mayoría parlamentaria, condición esencial para proceder a un proceso de desregulación burocrática e intereses creados.

Incluso si tal gobiemo fuese elegido, el cambio no sería inevitable. Es dable esperar una dura batalla entre quienes conforman los grupos de presión, tal como sucedió en Francia hace algunos meses atrás. También es posible que las reformas fallen en un primer intento y que aún sean necesarios algunos años más de lento crecimiento y dificultades crecientes para forzar a la población, en especial el sector privado, a decidir que el proceso de reformas es lo que realmente les interesa.

Y si la economía nos enseña una simple verdad, ella es que, al final, la gente se guía por sus propios intereses. El problema es que este "al final" puede tomar aún mucho tiempo. Y el Asia espera y el mundo espera. 